\title{
Immature myeloid cells are critical for enhancing bone fracture healing through angiogenic cascade
}

\author{
(Running Title: Immature myeloid cells in fracture healing)
}

Seth Levy ${ }^{1}$, Joseph M. Feduska ${ }^{1}$, Anandi Sawant ${ }^{1}$, Shawn Gilbert ${ }^{2}$, Jonathan A. Hensel ${ }^{1}$, and Selvarangan Ponnazhagan ${ }^{{ }^{*}}$

Departments of Pathology ${ }^{1}$ and Surgery ${ }^{2}$, The University of Alabama at Birmingham, Birmingham, $\mathrm{AL}$

*Corresponding author: Selvarangan Ponnazhagan, Ph.D., Department of Pathology, 1825

University Boulevard, SHEL 814, The University of Alabama at Birmingham, Birmingham, AL 35294-0007, Phone: (205) 934-6731; Fax (205) 975-9927,E-mail: pons@uab.edu

Keywords: Angiogenesis; Bone fracture; Bone marrow, Myeloid cell, Wound healing 


\begin{abstract}
Bone fractures heal with overlapping phases of inflammation, cell proliferation, and bone remodeling. Osteogenesis and angiogenesis work in concert to control many stages of this process, and when one is impaired it leads to failure of bone healing, termed a nonunion. During fracture repair, there is an infiltration of immune cells at the fracture site that not only mediate the inflammatory responses, but we hypothesize they also exert influence on neovasculature. Thus, further understanding the effects of immune cell participation throughout fracture healing will reveal additional knowledge as to why some fractures heal while others form nonunions, and lead to development of novel therapeutics modulating immune cells, to increase fracture healing and prevent nonunions. Using novel femoral segmental and critical-size defect models in mice, we identified a systemic and significant increase in immature myeloid cell (IMC) infiltration during the initial phase of fracture healing until boney union is complete. Using gemcitabine to specifically ablate the IMC population, we confirmed delayed bone healing. Further, adoptive transfer of IMC increased bone growth in a nonunion model, signifying the role of this unique cell population in fracture healing. We also identified IMC post-fracture have the ability to increase endothelial cell migration, and tube formation, signaling the essential communication between the immune system and angiogenesis as a requirement for proper bone healing. Based on this data we propose that IMC may play a significant role in fracture healing and therapeutic targeting of IMC after fracture would minimize the chances of eventual nonunion pathology.
\end{abstract}




\section{INTRODUCTION}

Each year, approximately 10-20\% of the 6 million bone fractures in the United States will fail to heal, progressing to a condition termed nonunion (Canale 2003). Nonunion is defined as a fracture which has not healed 9 months post-occurrence, and has not shown any radiological progress within 3 months (Summers 2011). Nonunion occurs due to underlying pathologies that lead to either the fracture callus failing to fully ossify, or in atrophic cases, not forming altogether. At this point, aggressive and invasive treatment is required, which is associated with increased pain, disability, and treatment cost (Bucholz 2002). The gold-standard treatment for nonunion is currently internal stabilization of the bone via an intramedullary pin and screws, followed by autologous bone grafts from the iliac crest to promote osteoinductive signals (Sen 2007). However, this procedure has numerous inherent risks, including invasiveness, poor mechanical stability offered by the bone graft alone, and limited availability of bone from the iliac crest (Khan 2005). Therefore, novel, noninvasive approaches for treating nonunions should be investigated.

Upon initial fracture, the traumatized tissues release various chemical signals, which recruits an influx of immune cells and osteogenic progenitors to fight infection and repair the fracture (Gerstenfeld 2003). Several of these growth factors and cytokines, such as vascular endothelial growth factor (VEGF), bone morphogenetic proteins (BMPs) and interleukins (IL) -1 and -6 have been well characterized in recruiting inflammatory mediators to the fracture site (Dimitriou 2005). Among the immune system cells are progenitors of the myeloid lineage, termed immature myeloid cells (IMCs). These IMCs comprise roughly 30\% of all bone marrow cells, and under normal conditions eventually differentiate to macrophages, dendritic cells, and granulocytes (Gabrilovich 2009). However, their direct involvement in the inflammatory process following bone fracture has yet to be determined.

IMC have been found to exert specific functions in other pathological contexts. In cancer, it was shown that IMC facilitate the induction of angiogenesis within tumors (Gabrilovich 2012). As with cancer, the injury site following fracture experiences elevated hypoxia as a byproduct of inflammation. It was recently shown that hypoxia-inducible factor (HIF) $1 \alpha$ couples angiogenesis with osteogenesis during bone early development (Wang 2007). Because nonunions are more likely to occur in conjunction with impaired angiogenesis (Brownlow 2002, Bahney 2015), we sought to investigate the role IMCs may play in the coordination of angiogenesis with osteogenesis during bone fracture repair.

In this study, we characterized the involvement of various immune cells at varying stages of fracture repair in a mouse model that mimics human bone fractures, and identified IMCs as exerting a critical influence on proper bone healing. Further characterization of the molecular mechanism of IMC-mediated bone repair suggested that IMC aid in the process of angiogenesis. These data provide evidence that IMC are critical for bone fracture healing and that IMC have 
potential as a therapeutic intervention leading to improved vascularization and bone growth, ameliorating the risk for fracture nonunion.

\section{MATERIALS AND METHODS}

\subsection{Cells and culture conditions:}

Human umbilical vein endothelial cells (HUVEC) were purchased from ATCC and grown in endothelial cell growth media (EGMTM-2, Lonza). Antibodies for mouse CD3,CD4, CD8, IL-4, CD25, FoxP3, IL-17, B220, CD49b, CD69, CD11b, CD11c, Flk-1, Gr-1, F4/80, Ly6C, used for fluorescent-activated cell sorting (FACS) were purchased from eBiosciences, Ly6G was purchased from BDPharmigen. For T-cell suppression assay, the IMC and T lymphocytes were isolated by FACS using standard markers (see below), and purified cells were grown in DMEM (Gibco) supplemented with 10\% fetal bovine serum (Gemini Bio-products) and 1\% penicillin/streptomycin (Gibco). The IMC and HUVEC for scratch, invasion, and tube formation assays were performed in endothelial cell basal media (EBM) (Lonza) either serum-free or supplemented with $2 \%$ fetal bovine serum (Gemini Bio-products).

\subsection{Femoral segmental bone defect:}

Eight-week-old female C57BL/6 mice were anesthetized with isoflurane inhalation at a concentration of $2.5 \%$. Upon confirming loss of consciousness, the fur was shaved and a longitudinal incision was made from hip to knee in the fascia between the quadriceps femoris (vastus lateralis) and biceps femoris. The sciatic nerve was severed to prevent excessive movement of the limb. The periosteum was stripped at the fracture site, and the underlying muscles were separated. External stainless steel fixators (fabricated by the Research Machine Shop, The University of Alabama at Birmingham) with attachment arms set $3 \mathrm{~mm}$ apart, were secured along the shaft of the femur with stainless steel ligature wire (3M Unitek). A Dremel 200 Series rotary tool affixed with a stainless steel circular bone saw $(1.6 \mathrm{~cm}$ diameter, $0.1 \mathrm{~mm}$ blade thickness; Fine Science Tools) introduced a single osteotomy through the midshaft of the femur between the opposing ends of the fixator. All animals were mobile after awakening from anesthesia. Mice were treated with Rimadyl (Pfizer Inc.) for pain in accordance with University of Alabama at Birmingham Animal Resource Program (ARP) recommendations.

\subsection{Radiographic evaluation:}

Radiographs were taken weekly using an MX-20 Faxitron x-ray machine at the UAB Small Animal Phenotyping core facility (Birmingham, AL). Images were attained at an energy level of $34 \mathrm{kV}$ for 10 seconds. Healing of segmental defect was considered complete when the fracture gap was completely bridged by bone, as seen by radiograph. Mechanical strength post-healing was not tested. If the fixator changed position from its original placement or lost proper alignment, the animal was not used for any analysis. 


\subsection{Evaluation of immune cells following femoral fracture in mice:}

Eight-week-old C57BL/6 mice were sacrificed and bone marrow cells were collected from the broken femur, adjacent tibia, and contralateral femur and tibia. Red blood cells were lysed using $\mathrm{RBC}$ lysis buffer (Promega). Cells were then incubated with $\mathrm{Fc}$ block for 15 minutes at $4^{\circ} \mathrm{C}$, then stained with antibodies for the following antigens for 30 minutes at $4^{\circ} \mathrm{C}$. Cells were then washed with PBS and fixed in $4 \%$ formalin. Flow cytometry analysis was performed on a BD LSR II flow cytometer and analyzed using FlowJo (Treestar) software.

T lymphocytes:

Th1 $\mathrm{CD}^{+} \mathrm{CD}^{+}{ }^{\mathrm{IFN}} \gamma^{+}$

$\mathrm{Th} 2: \mathrm{CD}^{+} \mathrm{CD} 4^{+} \mathrm{IL}-4^{+}$

Treg: $\mathrm{CD}^{+} \mathrm{CD} 4^{+} \mathrm{CD} 25^{+} \mathrm{FoxP} 3^{+}$

Th17: $\mathrm{CD}^{+} \mathrm{CD} 4^{+} \mathrm{IL}-17^{+}$

Cytotoxic T cells: $\mathrm{CD}^{+} \mathrm{CD}^{+}$

B lymphocytes: B220 ${ }^{+}$

Natural killer cells: CD49b ${ }^{+} \mathrm{CD}^{+} 9^{+}$

Dendritic cells: CD11 ${ }^{+} \mathrm{CD} 11 \mathrm{c}^{+}$

Neutrophils: Gr- $1^{+} \mathrm{Ly}_{6} \mathrm{~b}^{+}$

Macrophages: $\mathrm{CD} 11 \mathrm{~b}^{+} \mathrm{F} 4 / 80^{+}$

Immature myeloid cells: $\mathrm{Gr}-1^{+} \mathrm{CD} 11 \mathrm{~b}^{+} \mathrm{Ly} 6 \mathrm{C}^{+} \mathrm{Ly}_{6 \mathrm{G}}{ }^{-}$,

\subsection{Analysis of bone healing of a segmental defect with IMC depletion:}

To specifically deplete the IMC population, mice were injected intraperitoneally (IP) with gemcitabine (LKT Laboratories) at a dosing of $60 \mathrm{mg} / \mathrm{kg}$ in $100 \mu \mathrm{l}$. Gemcitabine was administered prior to defect surgery at Day -7 and Day -3, and following surgery at Day 1 and Day 7. Depletion of IMC was confirmed by flow cytometry using Gr-1 and CD11b antibodies. Prior to histology, radiographic analysis of the fracture area was performed in a Faxitron soft Xray machine (Faxitron X-Ray LLC, 575 Bond St. Lincolnshire, IL 60069 USA) in UAB Small Animal Bone Phenotyping Core (SABPC). Briefly, mice were anesthetized with isoflurane and imaging was performed for 2-10 seconds. For histology, femurs were harvested following sacrifice of mice on day-21 and fixed in $4 \%$ formalin for 72 hours. Femurs were then decalcified in $10 \%$ EDTA for two weeks and embedded in paraffin for staining with hematoxylin and eosin (H \& E) (UAB Bone Histomorphometry and Molecular Analysis Core).

\subsection{FACS and analytical flow cytometry:}

IMC were isolated by fluorescent-activated cell sorting (FACS) for use in in vitro assays and in vivo adoptive transfer studies. Eight-week-old C57BL/6 mice were sacrificed and bone marrow cells were collected. RBCs were lysed using ACK-RBC lysis buffer. Cells were incubated with Fc block for 15 minutes at $4^{\circ} \mathrm{C}$. For sorting of total IMC population, cells were stained with APC-conjugated anti-CD11b antibody and PE-Cy7-conjugated Gr-1 antibody (eBioscience) for 30 minutes at $4^{\circ} \mathrm{C}$. After washing with sterile PBS, CD $11 \mathrm{~b}^{+} \mathrm{Gr}-1^{+} \mathrm{IMC}$ were sorted using a BD ARIA III cell sorter (BD Biosciences). CD $11 \mathrm{~b}^{+} \mathrm{Gr}-1^{+} \mathrm{IMC}$ were further stained for additional 
markers including F4/80, Ly6C, Ly6G, and Flk-1 antibodies. Formation of reactive oxygen species and nitric oxide were detected by permeabilization of cells and staining with dihydroxyethidium (DHE, $10 \mu \mathrm{mol} / \mathrm{L}$; Molecular Probes) and DAF-FM (Life Technologies) respectively. The percentages of positive cells were determined by flow cytometry. Arginase-1 was detected using anti-Arg-1 and percentage of positive cells was determined by flow cytometry.

\subsection{In vitro suppression assay:}

Following sacrifice of naïve mice and mice with segmental defect, IMC were isolated from the bone marrow and CD4+ T cells were sorted from the spleen by flow cytometry. CD4+ T cells were then labeled with carboxyfluorescein diacetate succinimidyl ester (CFSE) as per the manufacturer's instructions (Molecular Probes). Following labeling, $\mathrm{CD}^{+}{ }^{\mathrm{T}}$ cells were cultured with IMC in a ratio of $1: 1$ in medium containing $0.75 \mu \mathrm{g} / \mathrm{ml}$ anti-CD3 and $4 \mu \mathrm{g} / \mathrm{ml}$ anti-CD28 antibodies along with $50 \mu \mathrm{M} \beta$-mercaptoethanol for $72 \mathrm{hrs}$. As a control CD4 ${ }^{+} \mathrm{T}$ cells were cultured in the absence of IMC. After $72 \mathrm{hrs}$, cells were harvested and presence of CD4 ${ }^{+} \mathrm{T}$ cells labeled with CFSE was detected by flow cytometry.

\subsection{Scratch assay:}

Scratch assay was performed as described earlier (Liang 2007). Briefly, HUVEC cells were grown to confluence in 24-well plates and scratched with the narrow end of a sterile p200 pipette tip. Media was changed to remove floating cells and replaced with serum-free endothelial cell basal medium (Lonza). Photomicrographs were taken at 200x magnification immediately after initial wounding, and the scratch area was measured. Transwell inserts were inserted to the wells, and IMC were placed in the upper chamber in the same serum-free endothelial basal media. Cells were then incubated at $37^{\circ} \mathrm{C}$ with $5 \% \mathrm{CO}_{2}$. After 12 hours, photomicrographs were again taken at 200x magnification and the scratch area was analyzed using Image J (NIH).

\subsection{Invasion assay:}

HUVEC $\left(1 \times 10^{4}\right)$ were plated onto the upper chambers of transwell invasion assay filter inserts (BD Bioscience) in serum-free endothelial cell basal medium (Lonza) in 24-well plates. IMC (1 $\mathrm{x} 10^{4}$ ) were added into the lower chambers, acting as a chemoattractant. The cells were allowed to invade for 4 hours, after which, cells that invaded through the pore were fixed in $4 \%$ formalin and stained with neutral red. Representative photomicrographs were taken at 40x magnification.

\subsection{Semi-quantitative reverse transcription PCR:}

Total RNA was isolated from IMC using TRIzol reagent (Invitrogen). Then, $1 \mu \mathrm{g}$ of total RNA was reversed-transcribed to cDNA with an iScriptcDNA synthesis kit (Bio-Rad). PCR amplification was carried out using primers specific for angiopoietin-1, angiopoietin-2, TWIST, CXCR4, c-Kit, and GAPDH using the following condition: preheating at $95^{\circ} \mathrm{C}$ for 2 minutes, denaturation at $95^{\circ} \mathrm{C}$ for 30 seconds, annealing at $58^{\circ} \mathrm{C}$ for 30 seconds, and extension at $72^{\circ} \mathrm{C}$ for 30 seconds in a 30 -cycle reaction, followed by final extension at $72^{\circ} \mathrm{C}$ for 5 minutes. PCR was 
carried out with the Dream Taq Green $2 \times$ PCR mix from Fermentas in a 50- $\mu \mathrm{L}$ reaction volume. The following PCR primer sequences were used:

Angiopoietin 1:

Forward 5'-CCTGCAGAAGCAACAACTGG-3'

Reverse 5'-TTCCTCCCTTTAGCAAAACACCT-3'

Angiopoietin 2:

Forward 5'-TCGCTGGTGAAGAGTCCAAC-3'

Reverse 5'-TCCTGGTTGGCTGATGCTAC-3'

TWIST:

Forward 5'-TGTCCGCGTCCCACTAGC-3'

Reverse 5'-TGTCCATTTTCTCCTTCTCTGGA-3'

CCR2:

Forward 5'-AGGAGCCATACCTGTAAATGCC-3'

Reverse 5'-TGTGGTGAATCCAATGCCCT-3'

CXCR4:

Forward 5'-TTACCCCGATAGCCTGTGGA-3'

Reverse 5'-CAGGAGAGGATGACGATGCC-3'

c-Kit:

Forward 5'-CCTCCAACGATGTGGGCAAG-3'

Reverse 5'-GCCTGGATTTGCTCTTTGTTGT-3'

GAPDH:

Forward 5'-ACATCATCCCTGCATCCACTG-3'

Reverse 5'-TCATTGAGAGCAATGCCAGC-3'

Thirty microliters of PCR mixture was separated on 2\% agarose gel for electrophoretic analysis. All semi-quantitative reverse transcription PCR (RT-PCR) assays were independently conducted at least 3 times.

\subsection{Western blot analysis:}

Whole-cell lysates were prepared using RIPA buffer containing protease and phosphatase inhibitors according to the manufacturer's instructions (Thermo Scientific). Protein concentrations were measured using a commercially available BCA protein assay kit (Thermo Scientific). For each sample, $100 \mu \mathrm{g}$ of protein was used to detect the levels of HIF-1 $\alpha$ and $\beta$ actin by Western blot analysis. Following denaturation, the samples were separated on a $10 \%$ polyacrylamide gel and transferred to nitrocellulose membranes (Millipore) followed by 
blocking with $2 \%$ non-fat milk and incubation with primary antibodies, overnight at $4{ }^{\circ} \mathrm{C}$. After washing, the primary antibody with $1 \mathrm{x}$ Tris-buffered saline with Tween-20 (TBST; $3 \times 10$ minutes), followed by incubation with secondary antibody, conjugated to horseradish peroxidase for 1 hour at room temperature, then washed with TBST again for 3 times and blots were incubated with enhanced chemiluminescence reagent (GE Healthcare Life Sciences) according to the manufacturer's instructions and developed in a Fuji LAS-3000 chemiluminescence developer. $\beta$-actin was used as a loading control.

\subsection{Femoral critical-size bone defect and adoptive transfer:}

The surgical procedures for establishing the critical size nonunion defect were identical to those stated earlier for the segmental defect, with the following exceptions. The attachment arms for the external fixators were set $5 \mathrm{~mm}$ apart versus $3 \mathrm{~mm}$ for the segmental defect. A dual osteotomy was performed to introduce a gap of $3 \mathrm{~mm}$ in the femur. For adoptive transfer, IMC were isolated from naïve mice or activated after segmental defect as described above. Approximately $3 \times 10^{6}$ IMC were injected 2, 7, and 13 days post-fracture systemically. Bone growth was determined by faxitron analysis and the distance of the fracture gap between bone ends were calculated using ImageJ $(\mathrm{NIH})$.

\subsection{IMC-MSC co-culture studies for osteogenic markers:}

In order to determine if adoptive transfer of activated IMC induces osteogenic differentiation of MSC, we performed co-culture studies using IMC and MSC, obtained from mice bearing fracture. The assay was performed in a transwell culture system where $5 \times 10^{4} \mathrm{MSC}$ were seeded in the top compartment and equal amount of IMC from naïve mice or mice bearing bone fracture in the bottom compartment. MSC were harvested after 4-7 days and RNA isolated for quantitative RT-PCR analysis using primers for bone sialoprotein, osteocalcin, and osterix. Values were normalized with GAPDH expression in each sample. The primers used for RT-PCR are:

ALP:

Forward 5-CTCCAAAAGCTCAACACCAATG-3'

Reverse 5'-ATTTGTCCATCTCCAGCCG-3'

BSP:

Forward 5-CGGAGGAGACAACGGAGAAG-3'

Reverse 5'-GTAAGTGTCGCCACGAAGCT-3'

Osteocalcin:

Forward 5'-CTGACCTCACAGATGCCAAGC-3'

Reverse 5'-TGGTCTGATAGCTCGTCACAAG-3' 
Osterix:

Forward 5'-TGAGGAAGAAGCCCATTCAC-3'

Reverse 3'-ACTTCTTCTCCCGGGTGTG-3'

\subsection{Statistical analysis:}

Data were analyzed by student's t-test. Values provided are the mean $\pm S E$, and the differences were considered significant if $P$ was less than 0.05 .

\section{RESULTS}

\subsection{Characterization of immature myeloid cells during fracture repair:}

To elucidate the role of inflammatory cells in bone healing, we first created a femoral segmental defect in C57BL/6 mice, and compared the resting state vs response state of bone marrow (BM) immune cells following fracture. We employed an open femoral fracture model consisting of an osteotomy stabilized by external fixation (Figure 1A). Immune cells at the fracture site were then isolated and characterized by flow cytometry at time points corresponding to known phases of fracture healing (Dimitriou 2005) and compared to cells isolated from non-fractured control mice ("Day 0"). Bone marrow was isolated from the fractured femur (BF), the adjacent tibia (AT), as well as the contralateral femur (CF) and tibia (CT) before fracture (Day 0), and at 1, 3, 7,14 , and 21 days post-fracture. The initial inflammatory phase occurs at day- 1 and is characterized by an influx of immune cells; day-3 begins the proliferative phase for MSC and new vasculature; at day-7 intramembranous and endochondral ossification begin; at day-14 the callus begins to mineralize; and at day- 21 woven bone is remodeled into lamellar bone (Dimitriou 2005). Among the immune cell population types analyzed, dendritic cells, B lymphocytes, natural killer cells, multiple subsets of T lymphocytes (Th1, Th2, Th17, Treg, and $\mathrm{CD}^{+}$), and macrophages, showed no significant difference between the control groups without fracture and mice with segmental defect at various stages after fracture (data not shown). There was, however, a significant increase in the presence of $\mathrm{CD} 11 \mathrm{~b}^{+} \mathrm{Gr}-1^{+}$immature myeloid cells (IMC). Cells bearing the expression profile of CD $11 \mathrm{~b}^{+} \mathrm{Gr}-1^{+}$were considered IMC for this study (Figures 1B\&C), with additional predominant expression of Ly6C, indicative of a monocyte phenotype. These IMC were further characterized as predominantly monocyte $\left(\mathrm{Ly} 6 \mathrm{C}^{+}\right)$and nonneutrophilic $\left(\mathrm{Ly}^{-} \mathrm{G}^{-}\right)$as shown in Figure 1B. This population contained approximately $8 \%$ of cells that also expressed the macrophage maturation marker F4/80. However there was no significant difference in F4/80 positive cells between control mice and that bearing bone fracture (data not shown). The IMC characterized above were also positive for the progenitor marker cKit by RT-PCR (Figure 1D), which suggested their immature, undifferentiated status. Flow cytometry failed to demonstrate expression of c-Kit on IMC, which suggests either mRNA was not well translated or the resultant protein was rapidly degraded. 
Results of this analysis demonstrated that there was a significant increase in IMC population on day-3 post-fracture (Figure 1C), which corresponds with the initiation of angiogenesis, but steadily decreased to basal level by day-21, to below $10 \%$, seen in control mice. This data provided the initial clue that IMC may correspond to enhancing angiogenesis post fracture as new blood vessels invade the hematoma and callus formation. We also found that although there was no significant change in $\mathrm{CD}^{+}$or $\mathrm{CD}^{+} \mathrm{T}$ cells following fracture, there was a decrease in $\mathrm{T}$ helper (Th) 1 cells with a concomitant increase in Th2 population (Supplementary Figure 2).

\subsection{IMC do not function as immunosuppressive MDSC:}

In normal homeostasis of hematopoietic stem cell (HSC) lineage differentiation, the progenitor cells of the myeloid lineage; immature myeloid cells (IMC), following which they differentiate rapidly into dendritic cells, macrophages, or granulocytic cell types (Wynn 2013). However, in pathological states such as cancer, the differentiation of IMC is greatly curtailed to facilitate immune suppression and immune evasion. Since we found the IMC population to be significantly increased following fracture and remained in the microenvironment until ossification of the callus began, and that dampening of $\mathrm{T}$ cell function and proliferation is known to be associated with fracture healing (Colburn 2009, Nam 2012), we tested if these IMC possessed immunosuppressive properties. We confirmed that the isolated IMC were not immunosuppressive by employing an in vitro T cell suppression assay. Splenic T cells were cocultured with either control IMC ("naïve" IMC) or IMC isolated 3 days post-fracture ("activated" IMC). Neither the naïve nor activated IMC inhibited T cell proliferation (Figure 2A). It is known that T cell suppression via myeloid-derived suppressor cells (MDSC) is effected through the production of arginase-1 (Arg-1), reactive oxygen species (ROS), and inducible nitric oxide synthase (iNOS) (Gabrilovich 2009). We therefore measured levels of these immune suppressor intermediates produced by IMC in our fracture model. IMC displayed low levels of NO and ROS, while demonstrating no change after fracture in arginase-1 levels (Figure 2 B-D).

\subsection{Depletion of IMC results in delayed fracture healing:}

We next determined if the increase in IMC population is critically involved in the process of fracture repair. To study this, we designed gain- and loss-of-function experiments that would preferentially deplete or enhance the IMC population before and after fracture healing. To deplete the IMC population, mice were treated with gemcitabine, a nucleoside analog that specifically decreases cells of the myeloid lineage, while not affecting other immune cell populations (Suzuki 2005). To specifically deplete the IMC population, mice were injected intraperitoneally (IP) with gemcitabine (LKT Laboratories) at a dosing of $60 \mathrm{mg} / \mathrm{kg}$ in $100 \mu 1$. Gemcitabine was administered prior to defect surgery at Day -7 and Day -3 , and following surgery at Day 1 and Day 7 thereafter to maintain a decreased level of IMC. Mice treated with gemcitabine showed a significant decrease in the IMC population from $29.6 \%$ to $6.88 \%$ of total bone marrow cells (Figure 3A). In order to confirm that the effects of gemcitabine treatment were specific to the IMC population, we conducted flow cytometry analysis on a panel of immune cell populations. Results of this study revealed no significant difference in $\mathrm{CD}^{+} \mathrm{T}$ cells, 
$\mathrm{CD}^{+} \mathrm{T}$ cells, Th1, and Th2, (Supplementary Figure 2), and Th17 cells, or B cells (data not shown) at any of the established time points following gemcitabine treatment.

Following confirmation of the specific depletion of the IMC population, we compared the fracture healing ability of gemcitabine-treated mice with control mice, using the femoral segmental defect model. Mice deficient in IMC showed an impaired ability to repair the segmental bone fracture. Histological and radiographic analysis showed impaired callus formation and mineralization after 21 days (Figure 3B). To further determine that gemcitabine does not negatively affect angiogenic differentiation of endothelial cells, and osteoblast cell differentiation of MSC, we performed endothelial proliferation assay of HUVEC and osteoblast differentiation of MSC, respectively with varying concentrations of gemcitabine. Results of these studies, shown in Figure 3C showed that there was no significant effect of gemcitabine on either osteoblastic differentiation or the ability of HUVEC cells to form microvasculature in vitro.

\subsection{Immature myeloid cells increase endothelial cell migration and motility:}

It has previously been shown that a subpopulation of differentiated CD34 /CD $14^{+}$monocytes isolated from human peripheral blood will co-express endothelial-specific surface antigens and grow tube-like structures when cultured under angiogenic stimulation (Schmeisser 2001). Furthermore, when co-cultured with carcinoma cells, $\mathrm{CD} 11 \mathrm{~b}^{+} \mathrm{Gr} 1^{+}$cells have been shown to differentiate into endothelial cells, and incorporate into the tumor vasculature (Yang 2004). Considering that angiogenesis and osteogenesis are strongly coupled during bone formation, and that characterization of normal IMC revealed a predominantly monocytic phenotype $\left(\mathrm{Ly}_{6 \mathrm{C}^{+}} \mathrm{Ly}_{6 \mathrm{G}}^{-}\right.$), we sought to determine if IMC in the bone fracture microenvironment displayed an angiogenic phenotype. To this end, IMC infiltrates isolated from the site of broken femur were co-cultured with HUVEC in transwell migration, and motility assays in serum-free media to demonstrate factors from IMC were responsible for any changes in HUVEC phenotype. Results of this study, shown in Figure 4A demonstrated that IMC, isolated on day-3 and day-7 following bone fracture have the potential to initiate migration of endothelial cells. Additionally, utilizing a scratch assay, we further confirmed that activated IMC caused an increase in cell migration with significant migration observed in HUVEC, co-cultured with IMC isolated on days 3 and 7 after fracture (Figure 4B). These results indicate IMC in the post-fracture milieu aid in endothelial cell recruitment during fracture repair.

\subsection{Immature myeloid cells increase endothelial tube formation in vitro:}

To further elucidate the impact of IMC on angiogenesis in the bone fracture environment, we investigated whether isolated IMC could affect endothelial tube formation. IMC were isolated from wild-type and gemcitabine treated mice, both before and after segmental defect, and cocultured with HUVEC on reduced growth factor (RGF) Matrigel@. Naïve (control) and activated IMC attached to HUVEC cells and increased the number of branch points and the number of junctions significantly, compared to HUVEC cultured alone (Figure 5). This data confirmed IMC provide important paracrine effects on angiogenesis at the fracture site through soluble factors. 


\subsection{Angiogenic gene expression in activated IMC:}

Following our observation, which showed phenotypic modulation of endothelial cells by IMC, we next investigated possible mechanisms of how activated IMC are able to increase angiogenesis. We focused our efforts on key regulators of angiogenesis. Using gene transcripts from IMC, we determined the expression levels of angiopietin-1, angioepietin-2, TWIST, and CCR2 by semi-quantitative PCR. Analysis of the real-time PCR data revealed a stark upregulation in angiopoietin 1 and angiopoietin 2 levels (Figure 6A), known to increase not only the number of blood vessels but also the size and maturation of the vasculature (Fiedler 2006). A significant increase in TWIST, a key transcription factor, reported to increase angiogenesis and cell invasion in a variety of pathological states (Mironchik 2005, Stoletov 2010, Sun 2010), was also found to be significantly elevated (Figure 6A). In addition, there was a significant increase in CCR2 gene expression (Figure 6A), which has been reported to recruit inflammatory macrophages critical for angiogenesis (Willenborg 2012). Since angiopoietin-1 and -2 are downstream of HIF $1 \alpha$, a master regulator of angiogenesis (Dayan 2008), we determined HIF1 $\alpha$ levels in control, and activated IMC by Western blot. Results of this study, shown in Figure 6B, indicated a sharp increase in HIF1 $\alpha$ in activated IMC. These findings provide a clue on a possible mechanism of how activated IMC are able to increase angiogenesis.

\subsection{Adoptive transfer of IMC increase bone growth in critical-size defect:}

After confirming that depletion of IMC delays healing of segmental defect, we reasoned that adoptive transfer of IMC during the critical phase of the bone healing cascade in nonunion fracture should induce significant healing. To test this, a novel critical-size defect model, recapitulating atrophic nonunion, was created in C57BL/6 mice by removal of $3 \mathrm{~mm}$ of the femur and stabilized with external fixation. Prior to testing IMC, the $3 \mathrm{~mm}$ defect was confirmed to be a nonunion after 10 weeks. Approximately $3 \times 10^{6} \mathrm{IMC}$ were adoptively transferred into mice bearing the femoral critical defect. Donor IMC $\left(\mathrm{Gr}^{+} \mathrm{CD}^{+} 1 \mathrm{~b}^{+}\right)$, were isolated from wildtype mice ("naïve" IMC) or from mice 3 days following segmental defect ("activated" IMC). New bone formation was monitored by faxitron every two weeks and the distance between bone ends in the fracture gap were measured in ImageJ (Figure 7 A). Results of this study demonstrated that adoptive transfer of activated IMC significantly improved fracture healing by inducing more bone growth by 6 weeks post fracture compared to mice with no adoptive transfer or mice that received naïve IMC ( $\mathrm{p}<0.05)$. However, this increase in bony bridging was not sufficient to heal the fracture completely as there was no significant increase in new bone formation beyond week-6 (data not shown). To determine if adoptively-transferred activated IMC induced angiogenic response, and enhanced induction of osteogenic differentiation of MSC in the microenvironment, we performed a co-culture assay using activated IMC and MSC. As an indication of angiogenic response, we determined Tie-1, Tie-2 and VEGFR-2 in isolated IMC and as an indication of osteogenic signaling, gene expression levels of alkaline phosphatase (ALP), bone sialoprotein (BSP), osteocalcin, and osterix (OSX) were determined in MSC after 7 days of co-culture. Results of this study, provided in Figure 7B, indicated a significant increase 
inTIE-1, TIE-2, VEGFR-2, BSP, osteocalcin, and OSX when co-cultured with activated IMC. Taken together with the results of gemcitabine treatment for IMC depletion that resulted in a failure to heal bone fracture in a segmental defect model, and data shown in Figure 6 that activated IMC showed a significant increase in Ang1, Ang2, TWIST and CCR2, this data further confirmed that IMC primed in the fracture area play a significant role in inducing bone growth through angiogenic and possibly osteogenic response.

\section{DISCUSSION}

Immature myeloid cells are a population of immune cells which under normal conditions mature into macrophages, dendritic cells, and granulocytes. IMC are also capable of suppressing the immune response of $\mathrm{T}$ lymphocytes and are known to induce angiogenesis within tumors (Gabrilovich 2009). Furthermore, Yang et al. reported that colorectal tumor cells co-injected with myeloid cells exhibited not only increased vessel density and maturation, but that myeloid cells can directly incorporate into the tumor endothelia (Yang 2004). The IMC compartment represents approximately $30 \%$ of the bone marrow in normal mice, yet their role as inflammatory mediators in bone fracture has not been elucidated. The present study identified a critical and novel role of IMC in fracture healing and how IMC influence the overlapping phases of inflammation, angiogenesis, and osteogenesis after bone fracture. Compared to normal fractures, mice treated with gemcitabine to selectively deplete IMC population demonstrated an inability to heal fractures, while adoptive transfer of IMC obtained only from mice bearing fractures in a critical size defect increased bone growth following fracture. Evaluation of IMC after fracture revealed a significant upregulation in the expression of angiogenic genes, and the ability to bind to and increase the motility and mobility of endothelial cells in vitro. Results of these studies clearly demonstrate IMC likely contributed to the growth and formation of blood vessels after bone fracture and their presence was vital for proper fracture healing.

Recent evidence suggests that the immune system plays a large and diverse role in wound healing. Myeloid cells have been shown to be critical for angiogenesis in healing skin (Willenborg 2012), ischemia (Capoccia 2008), and retinal degeneration (Fukuda 2013). Additionally, many studies have demonstrated the impact of the immune system on bone fracture (Colburn 2009, Toben 2011, Nam 2012). The complex process of bone healing couples osteogenesis and angiogenesis to control many stages of fracture healing, and the role of the immune system within that cascade has yet to be entirely illuminated. Our studies identified that among immune cells at the fracture area, the IMC are expected play a key role in increasing angiogenesis in the bone fracture microenvironment.

Angiogenesis after fracture occurs initially during hematoma formation. As chondrocytes become hypertrophic and form bone, the IMC population increases after fracture and remains elevated until the fracture begins to mineralize, when the IMC population significantly decreases until boney union has occurred at day 21 . Recent studies have demonstrated that hematopoietic 
stem cells that have high c-Kit expression have increased proliferation but impaired self-renewal (Agarwal 2013, Shin 2014). Thus, elevated c-Kit levels may not only account for the significant increase in IMC population, but also to their decline in numbers after 14 days of increased proliferation.

After bone fracture, there is extensive tissue damage that leads to a secretion of a wide variety of growth factors and cytokines such as SDF-1, BMP-2, and VEGF, for example. The IMC isolated from the fracture area were positive for the major chemotactic factor receptors CXCR4

(Supplemental Figure 3), and Flk-1 (VEGFR-2). It is likely that these factors and others play a key role in mobilizing and increasing the proliferation of IMC and many other cells including osteoprogenitors after fracture. We characterized the systemic increase in IMC throughout bone healing until the time of boney union in wild-type mice (21 days). We also evaluated dendritic cells, macrophages, B lymphocytes, and multiple subtypes of T lymphocytes (Th1, Th2, Treg, Th17) by FACS analysis, but no other immune cell population displayed systemic or significant population shifts throughout bone fracture healing. Of note, while we did not detect changes in the overall levels of $\mathrm{CD}^{+}, \mathrm{CD}^{+}$naïve T cells, we did see a shift from Th1 to Th2 phenotype . The increased presence of IMC on day 3 after segmental defect correlated with the skew to a predominantly Th2 subset, though the total number of $\mathrm{CD}^{+}$cells did not change and was not altered in the presence of gemcitabine. This shift supports the idea that IFN- $\gamma$ producing Th1 cells inhibit endothelial cell proliferation while IL-6 producing Th2 cells are pro-angiogenic (Naldini 2003). This biphasic effect has been shown to in a multitude of pathologies including tissue repair after pathogenic infections, stress, and aging (Chensue 1996, Glaser 2001, Allen 2011).

The $\mathrm{Gr} 1^{+} \mathrm{CD} 11 \mathrm{~b}^{+} \mathrm{Ly} 6 \mathrm{C}^{+} \mathrm{Ly} 6 \mathrm{G}^{-}$profile of IMC correlates to a monocytic sub-type. It has been reported that monocytic MDSC are responsible for resistance to VEGF therapy in cancer as MDSC exert their angiogenic influence through molecules independent of VEGF, such as IL-1, IL-6, IL-8, tumor necrosis factor- $\alpha$ (TNF- $\alpha$ ), and basic fibroblast growth factor (bFGF) (Tartour 2011). MDSC also suppress T lymphocytes, B lymphocytes, neutrophils and other immune cells through cytokines or the release of nitric oxide, due to upregulated argniase-1 or inducible nitric oxide synthase (Gabrilovich 2009). However, the enriched IMC following bone fracture did not show a significant increase in either arginase-1 or inducible nitric oxide synthase as determined by FACS, and also lacked the ability to suppress splenic T cells. We have recently published that MDSC from tumor microenvironment in the bone marrow have the ability to differentiate into osteoclasts (Sawant 2013), but the IMC in the fracture microenvironment did not differentiate directly into osteoclasts (data not shown). Similarly, IMC isolated after fracture also did not display the ability to differentiate into osteoblasts. This proliferation of IMC and retention of an immature state during fracture healing suggests an alternative participation in the healing process, independent of direct involvement in osteogenesis.

Treatment with gemcitabine significantly lowered the presence of IMC after bone fracture and also decreased the ability of the mice to form boney union after segmental defect. Gemcitabine is 
thought to be specific for myeloid cells (Suzuki 2005, Le 2009) and in our studies it did not significantly alter any other evaluated immune cell populations. Further, when MSC differentiation was tested in the presence of gemcitabine there was no change in the pluripotency of MSC to differentiate into osteoblasts. Additionally, when the tube formation ability of HUVEC in the presence of gemcitabine was evaluated, no significant change was observed in the number of branches or the number of junctions. These data suggests that the gemcitabine treatment selectively decreased the presence of IMC and this decrease was responsible for a delay in boney bridging of the segmental defect. This result was further confirmed by the adoptive transfer of activated IMC (IMC isolated post-segmental defect) into the critical defect model, showing an increase in bone growth. Based on additional data characterizing IMC from the fracture site that indicated a significant increase in the expression of angiogenesis-related genes we suggest that IMC may play a crucial role during early phases of fracture healing and additional osteogenic induction may be required to complete the bridging of non-union fractures. Overall, the present study gives a new understanding to the role of the immune system in the healing of bone fractures, especially the significance of IMC during critical phases of osteogenesis following fracture. Further evaluation of molecular mechanisms involved in IMC mobilization and coupling signaling events should enable application of these findings towards healing critical size defects when they are presented at the clinic. Evidence from this study adds to an intriguing role of the IMC and the impact of naïve cell populations before maturation and differentiation on bone physiology.

\section{ACKNOWLEDGEMENTS}

This work was support by NIH R01AR060948, and DoD PR141945 grants . The authors thank Marion Spell and Enid Keyser (UAB Comprehensive Flow Cytometry Core) for their technical support for fluorescent activated cell sorting (FACS). The authors also thank Xuemei Cao (UAB Small Animal Phenotyping Core) for support in obtaining radiographs, and Dezhi Wang (UAB Histomorphometry and Molecular Analysis Core) with tissue processing and histology. 


\section{REFERENCES}

Agarwal, S., J. U. Kazi and L. Ronnstrand (2013). "Phosphorylation of the activation loop tyrosine 823 in c-Kit is crucial for cell survival and proliferation." J Biol Chem 288(31): 2246022468.

Allen, J. E. and T. A. Wynn (2011). "Evolution of Th2 immunity: a rapid repair response to tissue destructive pathogens." PLoS Pathog 7(5): e1002003.

Bahney, C. S., D. P. Hu, T. Miclau, 3rd and R. S. Marcucio (2015). "The multifaceted role of the vasculature in endochondral fracture repair." Front Endocrinol (Lausanne) 6: 4.

Brownlow, H. C., A. Reed and A. H. Simpson (2002). "The vascularity of atrophic non-unions." Injury 33(2): 145-150.

Bucholz, R. W. (2002). "Nonallograft osteoconductive bone graft substitutes." Clin Orthop Relat Res(395): 44-52.

Canale, S. T. and W. C. Campbell (2003). Campbell's operative orthopaedics. St. Louis, Mosby.

Capoccia, B. J., A. D. Gregory and D. C. Link (2008). "Recruitment of the inflammatory subset of monocytes to sites of ischemia induces angiogenesis in a monocyte chemoattractant protein-1dependent fashion." J Leukoc Biol 84(3): 760-768.

Chensue, S. W., K. S. Warmington, J. H. Ruth, P. S. Sanghi, P. Lincoln and S. L. Kunkel (1996). "Role of monocyte chemoattractant protein-1 (MCP-1) in Th1 (mycobacterial) and Th2 (schistosomal) antigen-induced granuloma formation: relationship to local inflammation, Th cell expression, and IL-12 production." J Immunol 157(10): 4602-4608.

Colburn, N. T., K. J. Zaal, F. Wang and R. S. Tuan (2009). "A role for gamma/delta T cells in a mouse model of fracture healing." Arthritis Rheum 60(6): 1694-1703.

Dayan, F., N. M. Mazure, M. C. Brahimi-Horn and J. Pouyssegur (2008). "A dialogue between the hypoxia-inducible factor and the tumor microenvironment." Cancer Microenviron 1(1): 5368.

Dimitriou, R., E. Tsiridis and P. V. Giannoudis (2005). "Current concepts of molecular aspects of bone healing." Injury 36(12): 1392-1404.

Fiedler, U. and H. G. Augustin (2006). "Angiopoietins: a link between angiogenesis and inflammation." Trends Immunol 27(12): 552-558.

Fukuda, S., M. Nagano, T. Yamashita, K. Kimura, I. Tsuboi, G. Salazar, S. Ueno, M. Kondo, T. Kunath, T. Oshika and O. Ohneda (2013). "Functional endothelial progenitor cells selectively recruit neurovascular protective monocyte-derived F4/80(+)/Ly6c(+) macrophages in a mouse model of retinal degeneration." Stem Cells 31(10): 2149-2161. 
Gabrilovich, D. I. and S. Nagaraj (2009). "Myeloid-derived suppressor cells as regulators of the immune system." Nat Rev Immunol 9(3): 162-174.

Gabrilovich, D. I., S. Ostrand-Rosenberg and V. Bronte (2012). "Coordinated regulation of myeloid cells by tumours." Nat Rev Immunol 12(4): 253-268.

Gerstenfeld, L. C., T. J. Cho, T. Kon, T. Aizawa, A. Tsay, J. Fitch, G. L. Barnes, D. T. Graves and T. A. Einhorn (2003). "Impaired fracture healing in the absence of TNF-alpha signaling: the role of TNF-alpha in endochondral cartilage resorption." J Bone Miner Res 18(9): 1584-1592.

Glaser, R., R. C. MacCallum, B. F. Laskowski, W. B. Malarkey, J. F. Sheridan and J. K. KiecoltGlaser (2001). "Evidence for a shift in the Th-1 to Th-2 cytokine response associated with chronic stress and aging." J Gerontol A Biol Sci Med Sci 56(8): M477-482.

Khan, S. N., F. P. Cammisa, Jr., H. S. Sandhu, A. D. Diwan, F. P. Girardi and J. M. Lane (2005). "The biology of bone grafting." J Am Acad Orthop Surg 13(1): 77-86.

Le, H. K., L. Graham, E. Cha, J. K. Morales, M. H. Manjili and H. D. Bear (2009). "Gemcitabine directly inhibits myeloid derived suppressor cells in BALB/c mice bearing 4T1 mammary carcinoma and augments expansion of T cells from tumor-bearing mice." Int Immunopharmacol 9(7-8): 900-909.

Liang, C. C., A. Y. Park and J. L. Guan (2007). "In vitro scratch assay: a convenient and inexpensive method for analysis of cell migration in vitro." Nat Protoc 2(2): 329-333.

Mironchik, Y., P. T. Winnard, Jr., F. Vesuna, Y. Kato, F. Wildes, A. P. Pathak, S. Kominsky, D. Artemov, Z. Bhujwalla, P. Van Diest, H. Burger, C. Glackin and V. Raman (2005). "Twist overexpression induces in vivo angiogenesis and correlates with chromosomal instability in breast cancer." Cancer Res 65(23): 10801-10809.

Naldini, A., A. Pucci, C. Bernini and F. Carraro (2003). "Regulation of angiogenesis by Th1- and Th2-type cytokines." Curr Pharm Des 9(7): 511-519.

Nam, D., E. Mau, Y. Wang, D. Wright, D. Silkstone, H. Whetstone, C. Whyne and B. Alman (2012). "T-lymphocytes enable osteoblast maturation via IL-17F during the early phase of fracture repair." PLoS One 7(6): e40044.

Sawant, A., J. Deshane, J. Jules, C. M. Lee, B. A. Harris, X. Feng and S. Ponnazhagan (2013). "Myeloid-derived suppressor cells function as novel osteoclast progenitors enhancing bone loss in breast cancer." Cancer Res 73(2): 672-682.

Schmeisser, A., C. D. Garlichs, H. Zhang, S. Eskafi, C. Graffy, J. Ludwig, R. H. Strasser and W. G. Daniel (2001). "Monocytes coexpress endothelial and macrophagocytic lineage markers and form cord-like structures in Matrigel under angiogenic conditions." Cardiovasc Res 49(3): 671680 .

Sen, M. K. and T. Miclau (2007). "Autologous iliac crest bone graft: should it still be the gold standard for treating nonunions?" Injury 38 Suppl 1: S75-80. 
Shin, J. Y., W. Hu, M. Naramura and C. Y. Park (2014). "High c-Kit expression identifies hematopoietic stem cells with impaired self-renewal and megakaryocytic bias." J Exp Med 211(2): 217-231.

Stamatovic, S. M., R. F. Keep, M. Mostarica-Stojkovic and A. V. Andjelkovic (2006). "CCL2 regulates angiogenesis via activation of Ets-1 transcription factor." J Immunol 177(4): 26512661.

Stoletov, K., H. Kato, E. Zardouzian, J. Kelber, J. Yang, S. Shattil and R. Klemke (2010). "Visualizing extravasation dynamics of metastatic tumor cells." J Cell Sci 123(Pt 13): 23322341.

Summers, H. and D. S. Chan (2011). General Principles in the Assessment and Treatment of Nonunions, Orthopaedic Trauma Association.

Sun, T., N. Zhao, X. L. Zhao, Q. Gu, S. W. Zhang, N. Che, X. H. Wang, J. Du, Y. X. Liu and B. C. Sun (2010). "Expression and functional significance of Twist1 in hepatocellular carcinoma: its role in vasculogenic mimicry." Hepatology 51(2): 545-556.

Suzuki, E., V. Kapoor, A. S. Jassar, L. R. Kaiser and S. M. Albelda (2005). "Gemcitabine selectively eliminates splenic Gr-1+/CD11b+ myeloid suppressor cells in tumor-bearing animals and enhances antitumor immune activity." Clin Cancer Res 11(18): 6713-6721.

Tartour, E., H. Pere, B. Maillere, M. Terme, N. Merillon, J. Taieb, F. Sandoval, F. QuintinColonna, K. Lacerda, A. Karadimou, C. Badoual, A. Tedgui, W. H. Fridman and S. Oudard (2011). "Angiogenesis and immunity: a bidirectional link potentially relevant for the monitoring of antiangiogenic therapy and the development of novel therapeutic combination with immunotherapy." Cancer Metastasis Rev 30(1): 83-95.

Toben, D., I. Schroeder, T. El Khassawna, M. Mehta, J. E. Hoffmann, J. T. Frisch, H. Schell, J. Lienau, A. Serra, A. Radbruch and G. N. Duda (2011). "Fracture healing is accelerated in the absence of the adaptive immune system." J Bone Miner Res 26(1): 113-124.

Wang, Y., C. Wan, L. Deng, X. Liu, X. Cao, S. R. Gilbert, M. L. Bouxsein, M. C. Faugere, R. E. Guldberg, L. C. Gerstenfeld, V. H. Haase, R. S. Johnson, E. Schipani and T. L. Clemens (2007). "The hypoxia-inducible factor alpha pathway couples angiogenesis to osteogenesis during skeletal development." J Clin Invest 117(6): 1616-1626.

Willenborg, S., T. Lucas, G. van Loo, J. A. Knipper, T. Krieg, I. Haase, B. Brachvogel, M. Hammerschmidt, A. Nagy, N. Ferrara, M. Pasparakis and S. A. Eming (2012). "CCR2 recruits an inflammatory macrophage subpopulation critical for angiogenesis in tissue repair." Blood 120(3): 613-625.

Wynn, T. A. (2013). "Myeloid-cell differentiation redefined in cancer." Nat Immunol 14(3): 197199. 
Yang, L., L. M. DeBusk, K. Fukuda, B. Fingleton, B. Green-Jarvis, Y. Shyr, L. M. Matrisian, D. P. Carbone and P. C. Lin (2004). "Expansion of myeloid immune suppressor Gr+CD11b+ cells in tumor-bearing host directly promotes tumor angiogenesis." Cancer Cell 6(4): 409-421. 


\section{FIGURE LEGENDS}

Figure 1. Characterization of immature myeloid cells from the fracture site:

A) Representative radiographs of segmental defect at day 1, day 7, day 14, and day 21 postfracture in C57BL/6 mice. Ossification of the fracture callus is clearly seen by day 14 , continuing to the bone remodeling phase by day 21. B) Bone marrow cells were isolated from control mice without fracture (Day 0) or from mice 3 days (Day 3) following femoral segmental defect (Day 3) IMC were detected based on the Gr- $1^{+} \mathrm{CD} 11 \mathrm{~b}^{+}$profile, and then further determined to be predominantly monocytic (Ly6C+Ly6G-). C) The percentage of IMC relative to all bone marrow cells was determined by flow cytometry before fracture (day 0 ), and day 1 , day 3 , day 7 , day 14 , day 21 post fracture ( $\mathrm{n}=3$ mice/time point $)(* \mathrm{P}<0.05 ; * * \mathrm{P}<0.01)$. D) Realtime PCR expression of hematopoietic progenitor cell marker c-Kit on IMC suggesting their progenitor cell state $(\mathrm{n}=3$ mice/time point) $* * \mathrm{P}<0.01$.

\section{Figure 2. Activated IMC are not immunosuppressive:}

A) In vitro $\mathrm{T}$ cell proliferation/suppression assay was performed with IMC as possible effectors of and CFSE-labeled splenic $\mathrm{T}$ cells as the target in T cell proliferation medium containing IL-2, and compared to control cultures without IMC. A shift towards the right side of the plot indicates proliferating T cells. All assays were performed with at least 3 mice/group/time point. B) Nitric oxide (NO), Reactive Oxygen Species (ROS), and Arginase-1 (Arg-1) levels in IMC population. IMCs were permeabilized and stained with dihydroxyethidium (DHE, $10 \mu \mathrm{mol} / \mathrm{L}$; Molecular Probes) to detect ROS, or DAF-FM (Life Technologies) to detect NO. The percentages of positive cells were determined by flow cytometry. Arginase- 1 was detected using anti-Arg- 1 and percentage of positive cells was determined by flow cytometry.

\section{Figure 3. Gemcitabine depletion of IMC population prevents boney union in segmental defect:}

A) Gemcitabine treatment results in significant depletion of Gr-1+CD11b+ IMC. B) H \& E staining and radiography of unhealed area in femoral segmental defect in wild-type mice (top) and gemcitabine treated mice (bottom) at 21 days post fracture. Relative quantitation of unhealed area following gemcitabine treatment, as compared to control is given on the right. Black arrows indicate fracture site, and failure to heal in gemcitabine-treated mice. $(\mathrm{P}<0.05)$ C) Gemcitabine does not inhibit MSC differentiation or HUVEC tube formation: MSC were differentiated in osteogenic differentiation media in the presence of gemcitabine. After 14 days MSC were stained with Alizarin Red for calcium deposition (top panel). HUVEC cells were cultured on reduced growth factor matrigel with normal basal endothelial cell medium with or without gemcitabine (bottom panel). Quantitative analyses from replicate experiments are provided on the right for each panel for both osteoblast differentiation of MSC and HUVEC tube formation. 
Figure 4. IMC isolated from fracture site increase endothelial cell migration, and motility: A) IMC isolated from naïve mice or mice after segmental fractures on days 1, 3, and 7were cocultured with HUVEC in serum-free medium. IMC were placed in the bottom chamber and HUVEC in the top of the Boyden chamber. HUVEC cells capable of passing though pores were fixed and stained with neutral red after 4 hours. B) HUVEC cell motility was performed using scratch assay in dual chamber tissue culture plate. Upon reaching confluence, a linear defect was introduced to HUVEC monolayers with a $200 \mu \mathrm{l}$ pipet tip. Naïve or activated IMC were placed in the upper compartment of Boyden chamber in serum-free media. Quantitative analysis of migrated HUVEC into the scratch area, provided on the right side, is expressed as percentage of migration as determined by closure of the gap width in indicated groups. $(\mathrm{P}<0.05$ compared to control and the group co-cultured with naïve IMC). Quantitative analyses of migration, and motility data from triplicate experiments are provided on the right $(* \mathrm{P}<0.05 ; * * \mathrm{P}<0.01$ compared to HUVEC alone, and using control IMC).

\section{Figure 5. Activated IMC increase endothelial tube formation:}

A) IMC isolated from naïve or 1, 3, or 7 days after segmental defect are co-cultured directly with HUVEC. IMC bind directly to HUVEC. IMC are labeled with CFSE, HUVEC with PKH26, 20x magnification. B) Representative images of HUVEC and IMC co-culture on tube formation assay. C) Quantitative analysis of tube formation using Angiogenesis Analyzer in ImageJ, $n=3$ and three $10 \mathrm{x}$ images per well $(* \mathrm{P}<0.05)$.

Figure 6. Upregulation of angiogenesis-related gene expression in activated IMC:

A) Quantitative real-time PCR was performed using RNA isolated from IMC from naïve or 1, 3, or 7 days after segmental bone fracture for angiopoietin-1 (Ang1), angiopoietin- 2 (Ang2), TWIST, CCR2, TIE1, and TIE2. All values were normalized to GAPDH levels ( $\mathrm{n}=3$ in triplicate; $* \mathrm{p}<0.05 ; * * \mathrm{*}<0.01)$. B) Western blot analysis for the expression of HIF-1 $\alpha$ in control (day-0) and activated (day-3 or day-7) IMC.

\section{Figure 7. Adoptive transfer of activated IMC increases bone growth in a critical-size} defect:

A) A femoral critical defect model was created where $3 \mathrm{~mm}$ of the femur was removed and the fracture stabilized with external fixators. Following creation of the fracture, $3 \times 10^{6}$ naïve or activated (obtained from donor mice on day3 after segmental defect) IMC were adoptively transferred into mice bearing critical-size defect $(n=6)$. Faxitron images were taken at 2, 4, and 6 weeks after creation of critical defect. Quantitate analysis shown on the right side indicates distance of fracture gap, measured in ImageJ $(* \mathrm{P}<0.05)$. B) Mesenchymal stem cells, isolated 
from mice bearing non-union fracture were co-cultured with control (wt IMC) or activated IMC (BF IMC) in transwell tissue culture plates for 7 days following which total RNA was isolated and analyzed from both IMC and MSC. Gene expression was determined by QRT-PCR for Tie1, Tie-2 from IMC, and for Alkaline Phosphatase (ALP), bone sialoprotein (BSP), osteocalcin, and osterix (OSX), involved in osteoblast differentiation ( $* \mathrm{P}<0.05)$. Expression of VEGFR-2 (Flk-1) on IMC was determined by flow cytometry. A shift in the peak towards right, shown in pink, represents IMC from fracture site as compared to control IMC in blue. 
A)

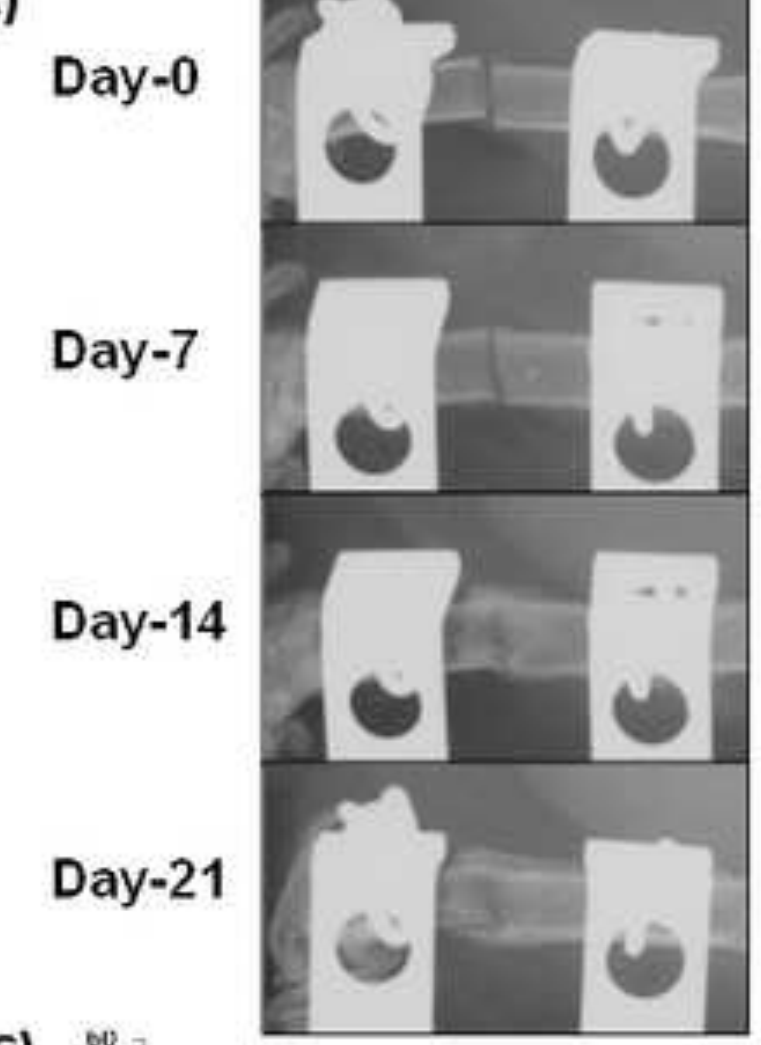

C)

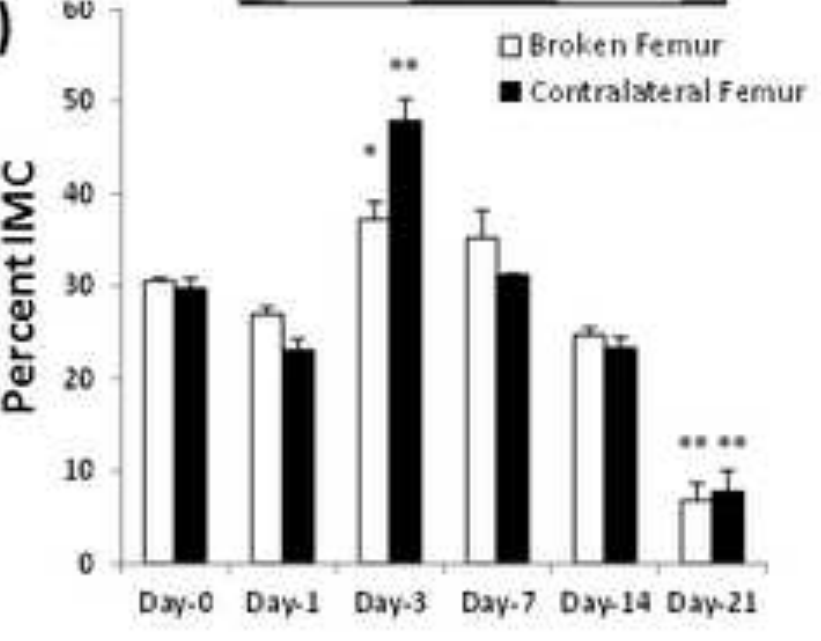

B) Day 0
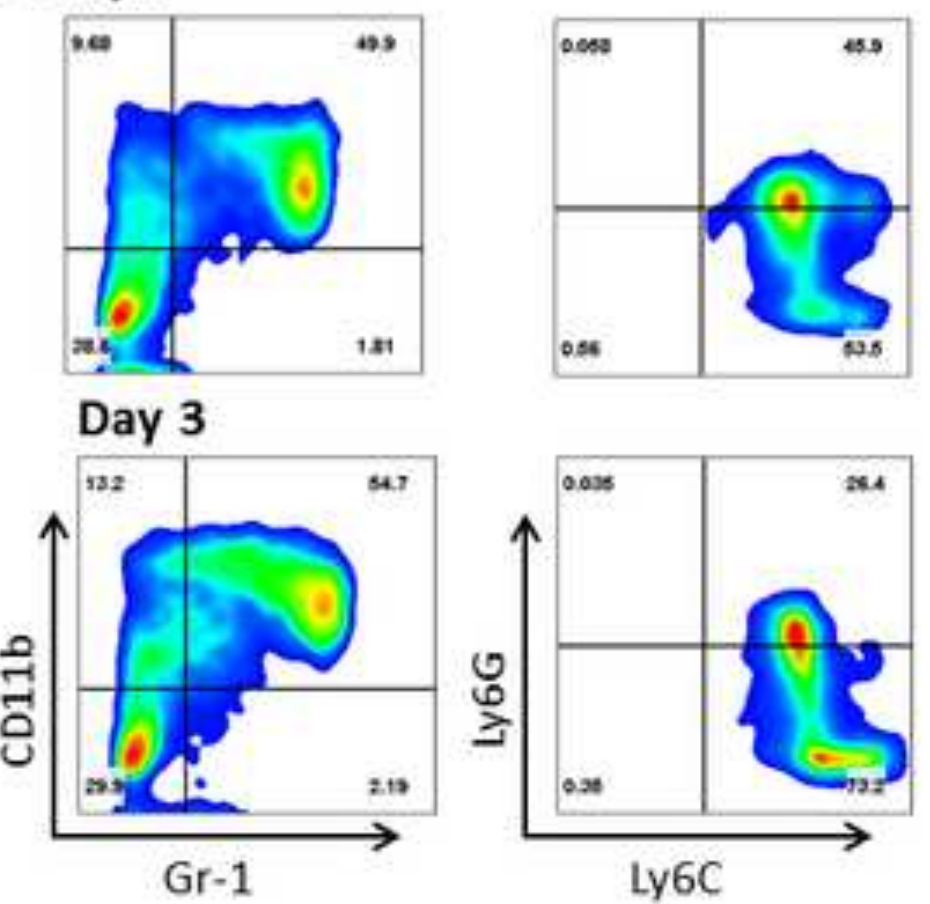

D)

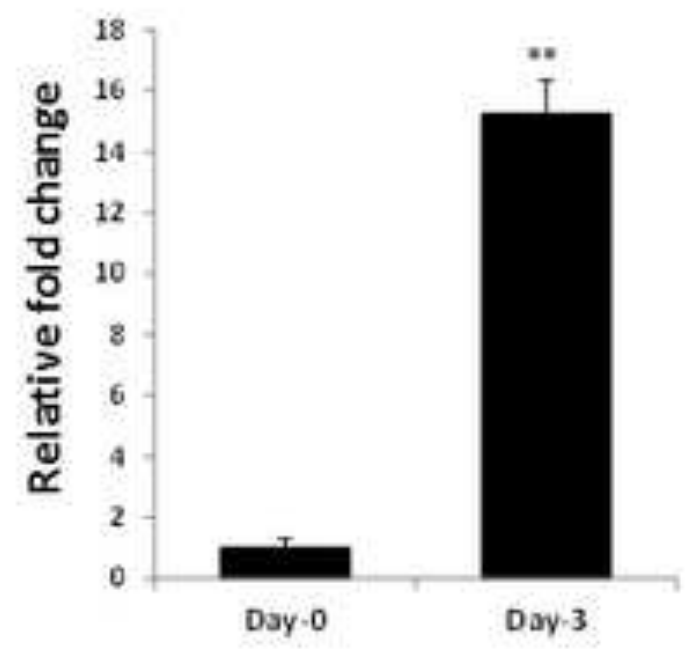

Figure 1 
A)

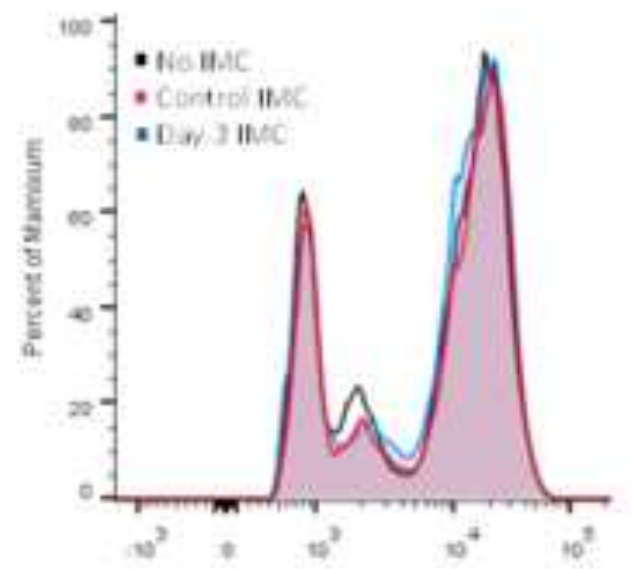

C)
B)
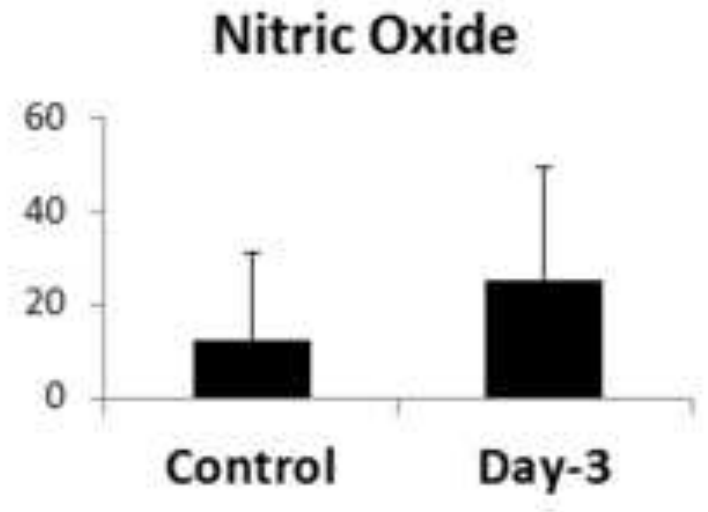

D)

Reactive Oxygen Species
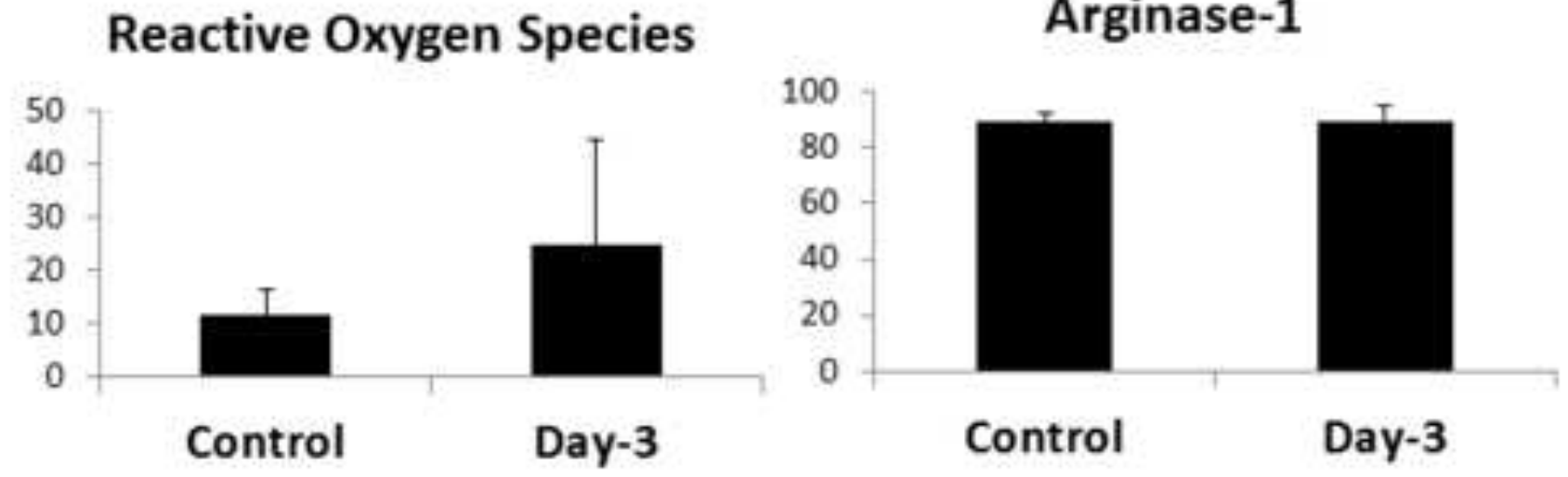

Figure 2 


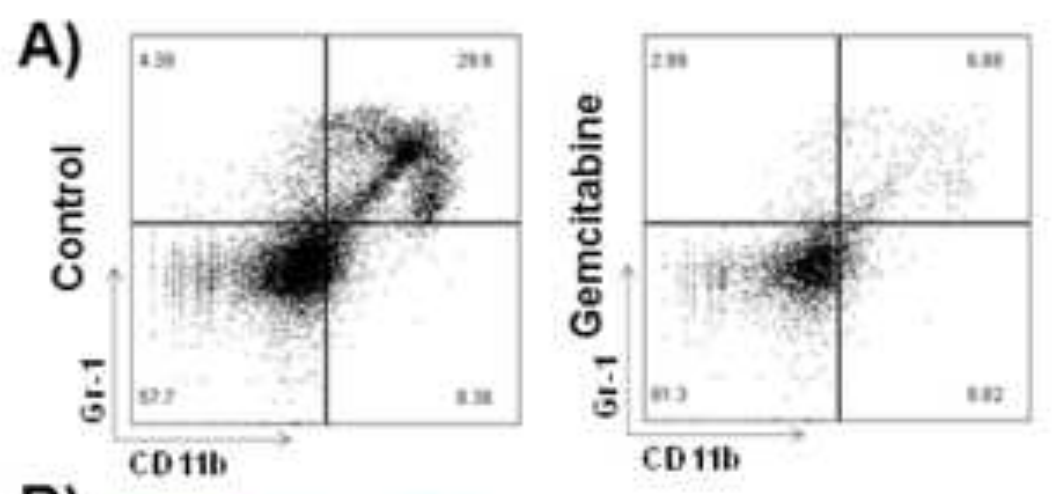

\section{B)}
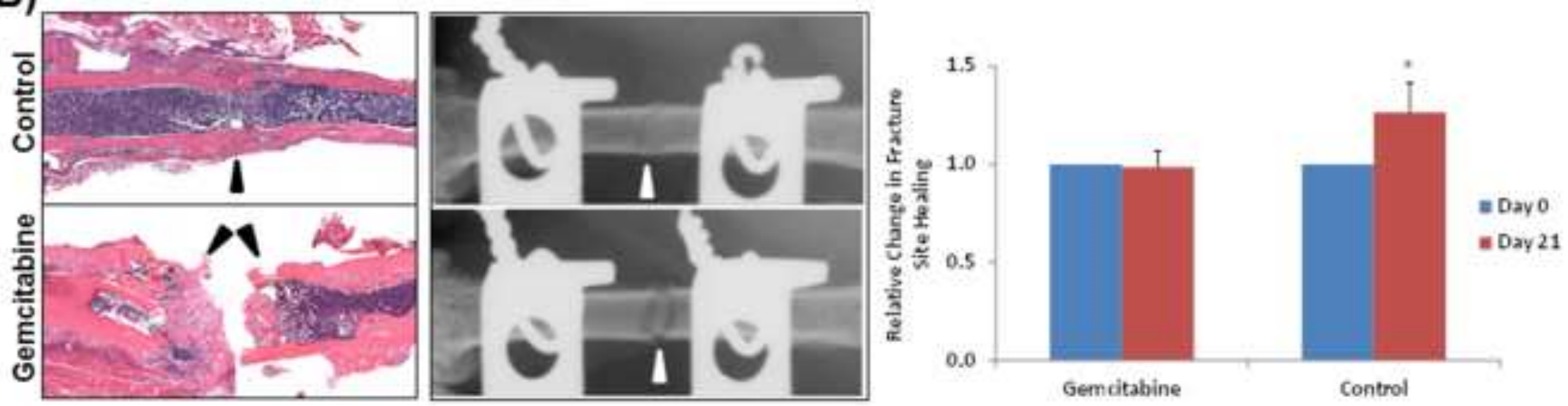

C)

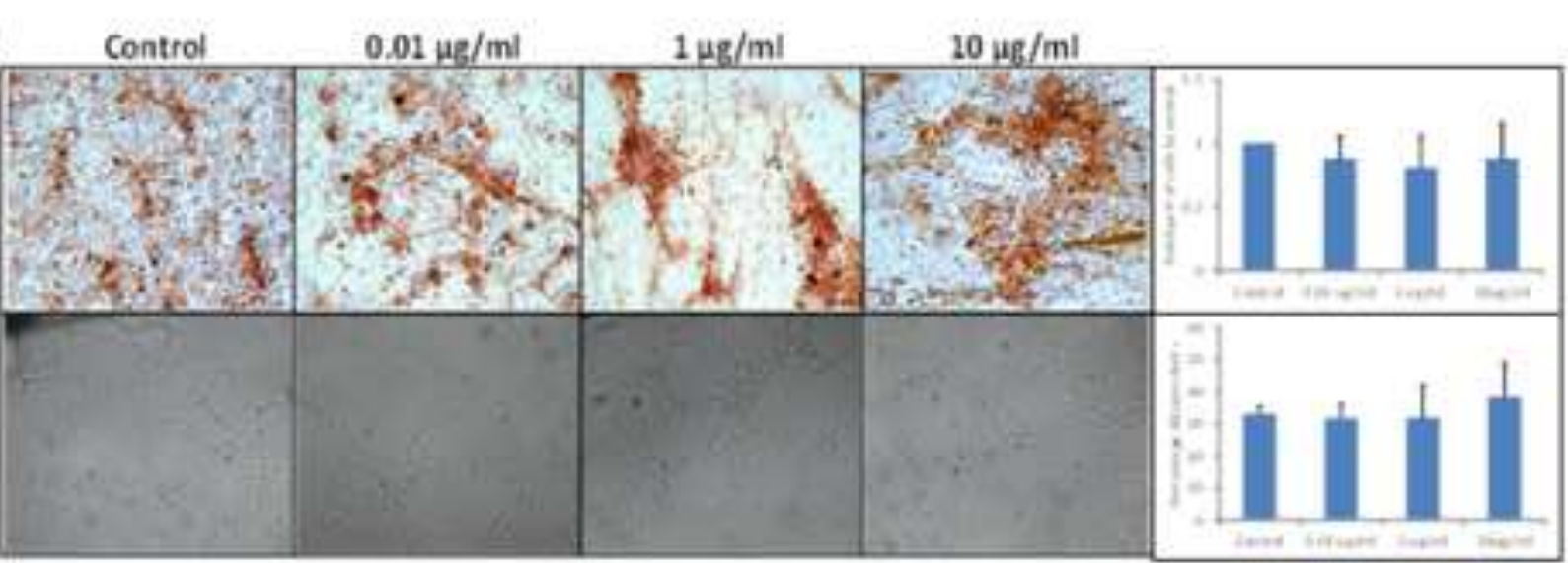

Figure 3 
A)
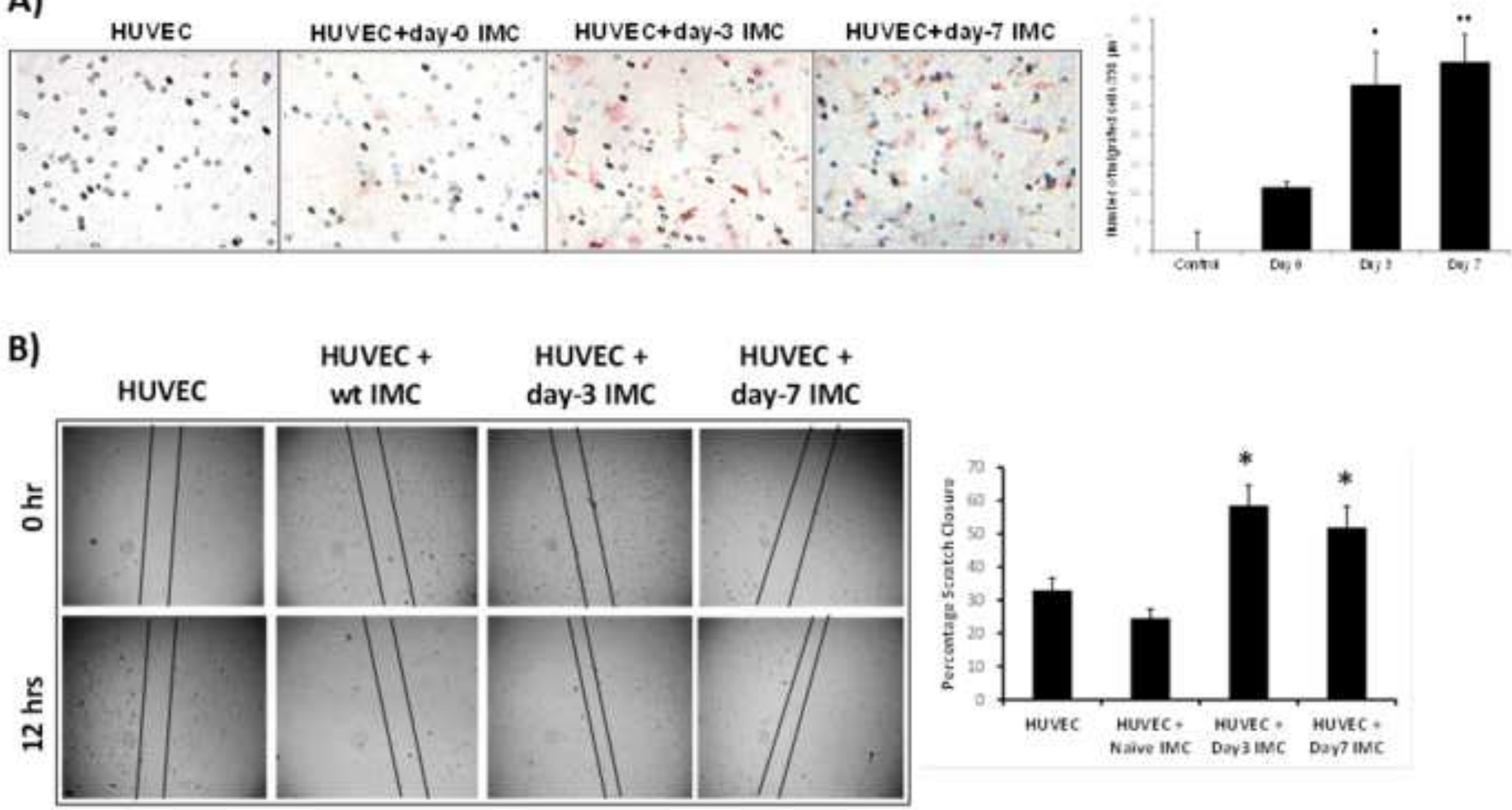

Figure 4 
A) HUVEC

Day-3 IMC

Merge
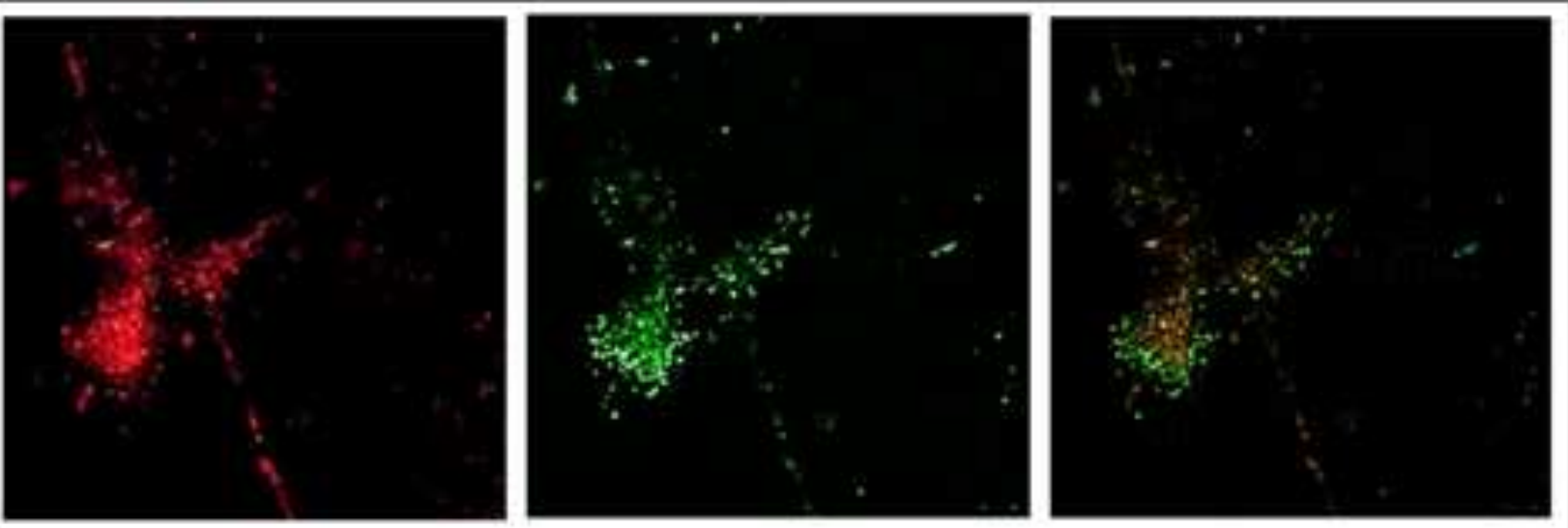

B)

HUVEC + day-0 IMC HUVEC + day-3 IMC HUVEC + day-7 IMC

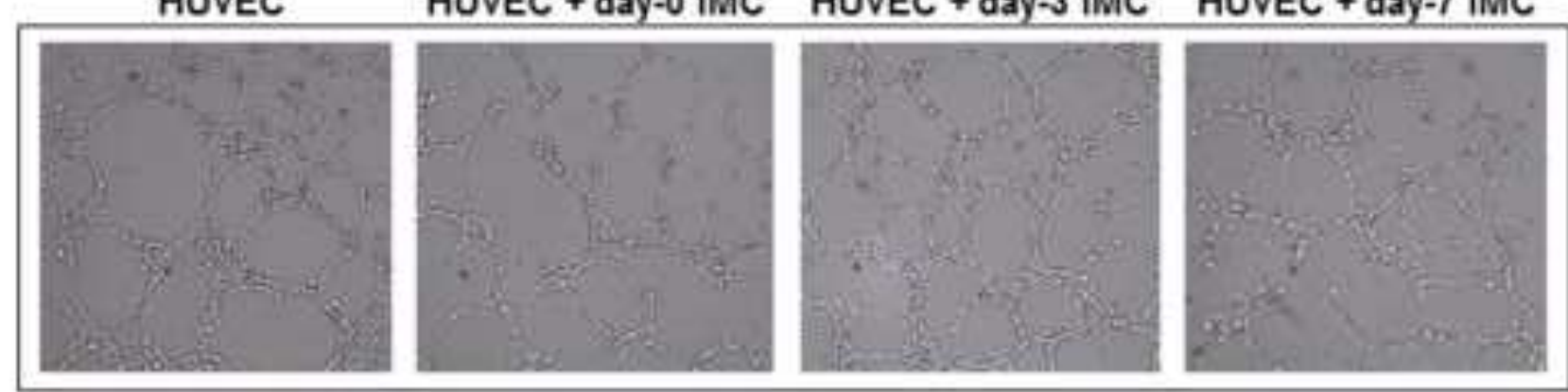

C)

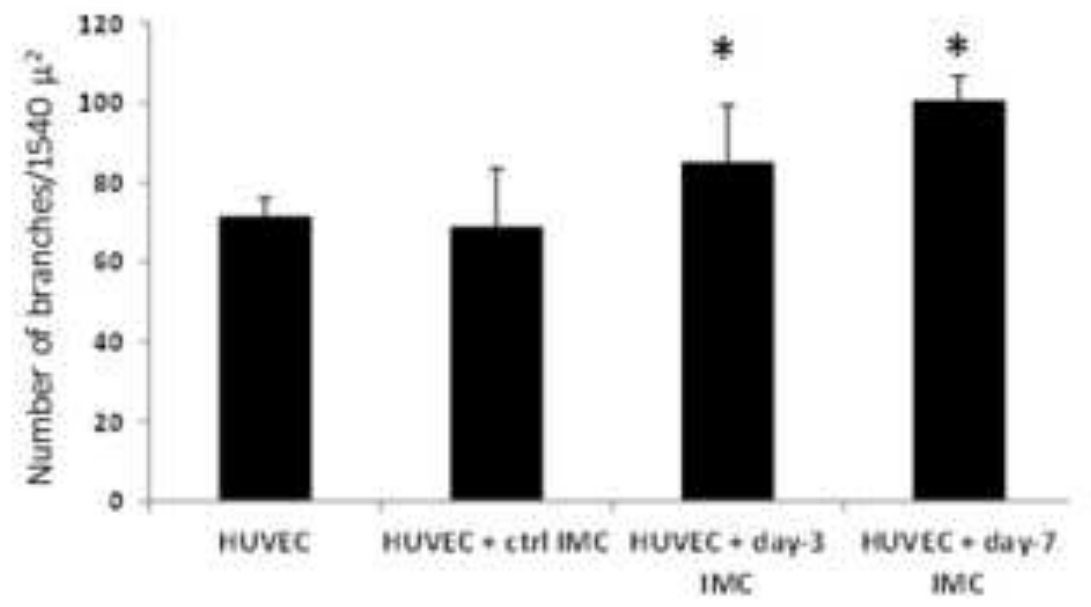

Figure 5 
A)

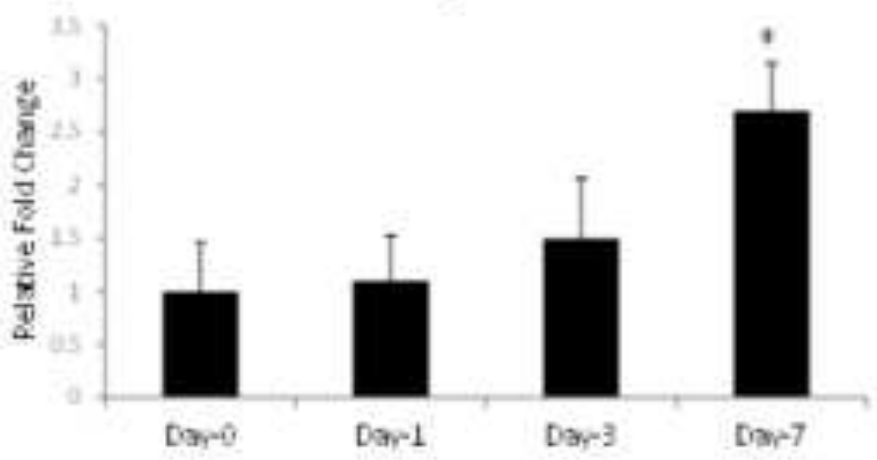

TWIST

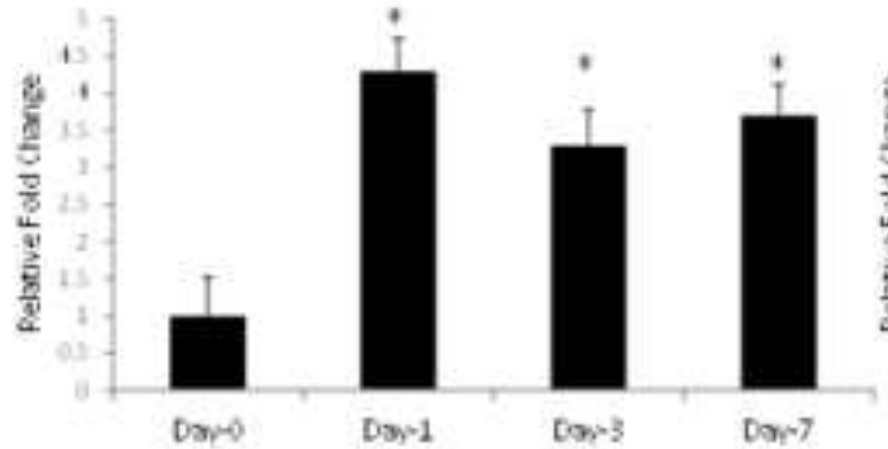

B)

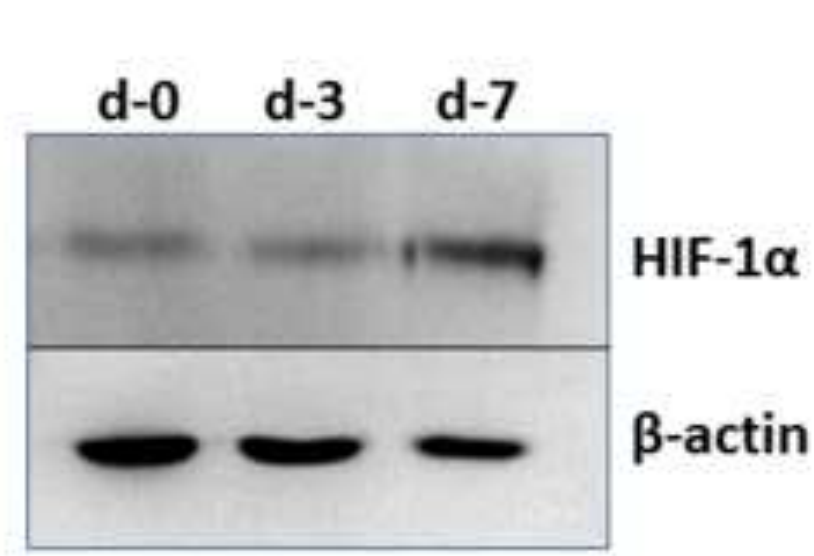

)
Ang 2

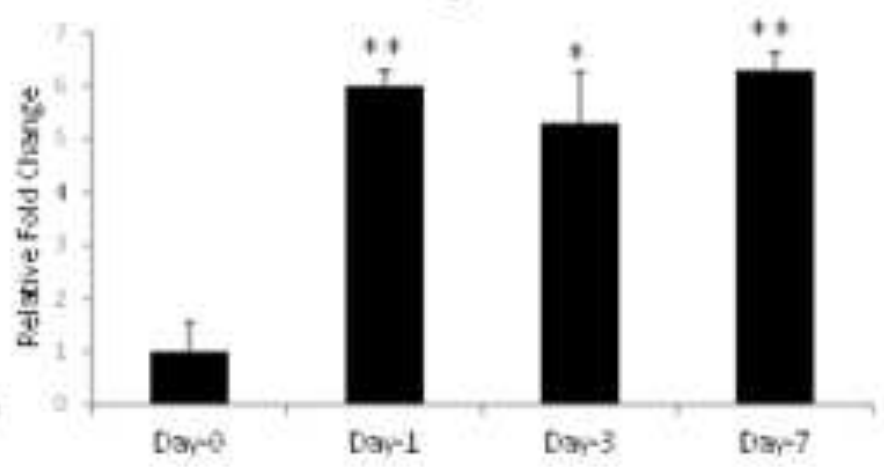

CCR2

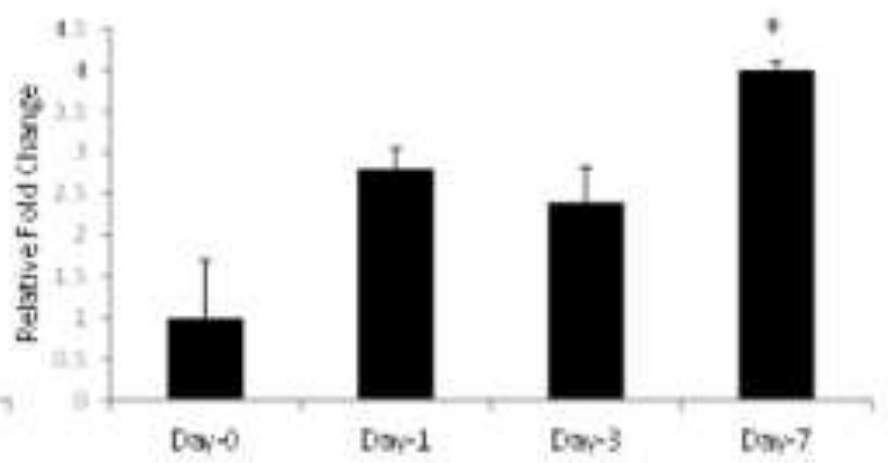

Figure 6 

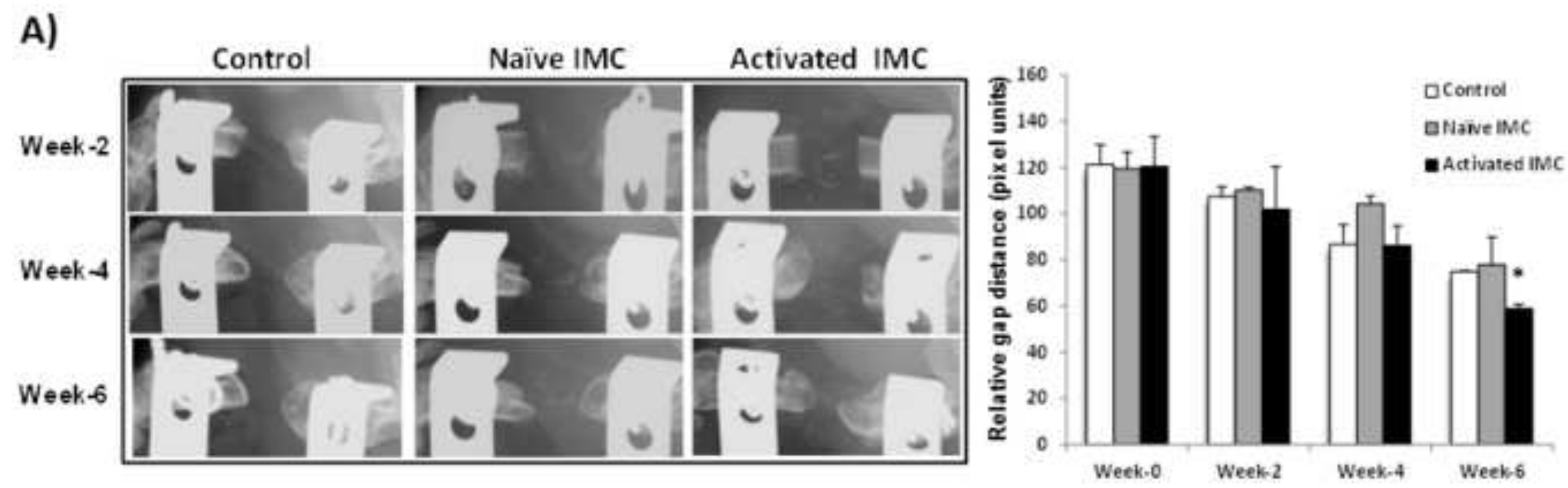

Figure 7A 
B)

Angiogenesis-related gene expression
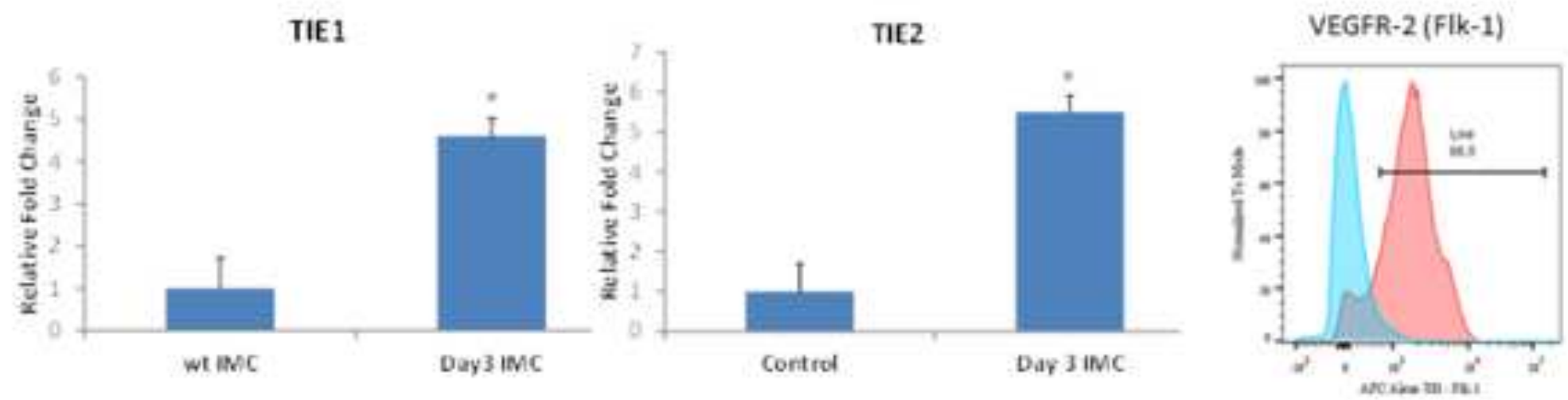

Expression of genes involved in osteoblast differentiation
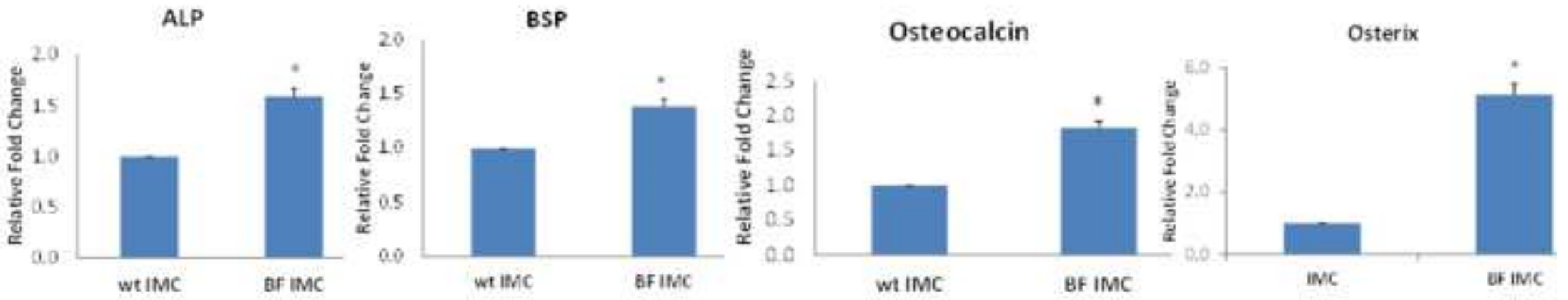

Figure 7B 